\title{
Influence of Drying Conditions on the Final Quality of Cherry and Grape Tomatoes
}

\author{
Heitor Otacílio Nogueira Altino ${ }^{1}$, Karyna Maria de Mello Locatelli ${ }^{2}$, Renata Nepomuceno \\ da Cunha ${ }^{2 *}$ \\ ${ }^{1}$ Universidade Federal de São Carlos, Departamento de Engenharia Química, São Carlos, São Paulo, Brasil. \\ ${ }^{2}$ Centro Universitário de Patos de Minas, Departamento de Engenharia Química, Patos de Minas, Minas Gerais, \\ Brasil.
}

\begin{abstract}
The convective drying process of cherry and grape tomatoes for dried tomato production was studied taking into account operational and sensorial aspects. The tomatoes were physicochemical characterized and dried at three air temperatures in a drying chamber. Thus, it was possible to the determinate the physicochemical characteristics, drying kinetics, thickness shrinkage, effective moisture diffusivity and activation energy. The effects of tomato type (cherry and grape), air temperature $\left(60^{\circ} \mathrm{C}\right.$ and $\left.80^{\circ} \mathrm{C}\right)$, and final moisture $(25 \%$ and $35 \%$ w.b.) were sensory evaluated utilizing a factorial experiment. The drying kinetics demonstrated that the drying processes occurred preferably in the falling rate-drying periods. The grape tomato showed a faster drying process, which was attributed to its higher surface area and also its internal structure. The sensory evaluation demonstrated that the cherry tomato, dried at lower air temperatures, resulted in better sensorial characteristics and higher purchasing intention, whereas the final moisture had no effect.
\end{abstract}

Keywords: Cherry tomatoes; Grape tomatoes; Drying; Sensory; Kinects.

*Author for correspondence: renatanepc@unipam.edu.br 


\section{INTRODUCTION}

Having a worldwide production of more than 170 million tons/year, tomatoes are considered as one of the most important produced vegetable crops. China, The United States, India, Turkey, and Egypt are the leading global nations in the production of tomatoes $[1,2]$. The tomatoes are mainly used in the fresh state and in some processes, such as sauces, canned verities, puree, and juices. In the fresh state, the tomato is highly perishable generating wastage and losses throughout the harvesting period [3]. Thus, in order to slow the microbiological activity and biochemical reactions responsible for the degradation of this fruit, the tomato is dried and used as component of several products such as pizza and various vegetable dishes [4,5]. Furthermore, the drying process can also provide reduction in weight, volume, costs of transportation, and storage [6].

The convective drying process is the most common process for dried tomato production. Nevertheless, the operational conditions such as air temperature, velocity, and moisture deeply affect the final quality of the product. This loss in quality is mainly due to the physicochemical changes during the process, e.g., shrinkage, migration of soluble solids, and loss of volatiles and aroma [3,7]. Thus, several studies were conducted in order to better understand the tomato drying process, as reported by $[3,4,7-9]$.

When it comes to dried tomato production, the cherry and grape tomatoes should be highlighted. They are plentiful, have good sensory characteristics, such as bright red color, sweet flavor and firm texture, and a significant nutritional value [10-12]. The drying process of the cherry tomato was studied by $[8,13,14]$ and the sensory acceptance of this fruit was demonstrated by [11]. Just a few studies of the drying process of the grape tomato are available in the literature, highlighting only [10] who studied the sun drying and rehydration of this type of tomato. However, although these tomatoes have appreciable qualities and very similar physiochemical characteristics, the convective drying process and sensory attributes of the grape tomato are not described in the literature. As a result, it is difficult to choose which one of them is the most appropriate type for dried tomato production, considering operational and sensorial aspects.

Thus, considering the qualities of cherry and grape tomatoes for dried tomato production, besides the absence of studies comparing both type of tomatoes taking in account operational and sensorial aspects. The aim of the present paper was to research the convective drying process of cherry and grape tomato for dried tomato production. In order to achieve this purpose, the tomatoes were physicochemical characterized and dried at three air temperatures in a drying chamber. Thus, it was possible to the determinate the physicochemical characteristics, drying kinetics, thickness shrinkage, effective moisture diffusivity and activation energy. The effects of tomato type, air temperature and final moisture on the final quality of the dried tomatoes were sensory evaluated utilizing a factorial experiment.

\section{MATERIALS AND METHODS}

\section{Raw Materials}

Fresh cherry (Lycopersicon esculentum var. cerasiforme) and grape (Lycopersicon esculentum Mill.) tomatoes were purchased from a standardized source in a local market in Patos de Minas, Minas Gerais, Brazil. In order to select the tomatoes, some criteria were evaluated, such as healthy fruits, reddish color, uniformity, cleaning and absence of mechanical and physiological damages. Thus, $2 \mathrm{~kg}$ of tomatoes were cleaned with deionized water $\left(\mathrm{CS} 1800\right.$, Permution $\left.{ }^{\circledR}\right)$ and sanitized with a $0.5 \%$ 
chlorine solution during $30 \mathrm{~min}$. Then, the tomatoes were physicochemical characterized, perpendicularly cut at the main axis (A), and gravitationally drained during $15 \mathrm{~min}$. All these procedures were done in such a way that the seeds were not lost.

\section{Physicochemical Characterization}

The initial moisture content was estimated by an Infrared Moisture Analyzer (IV 2500 , Gehaka ${ }^{\circledR}$ ), with an auto dry rate of $1 \% \cdot \mathrm{min}^{-1}$ and temperature of $105{ }^{\circ} \mathrm{C}$. In the interest of determining the particle size distribution, a granulometry analysis was done in each one of the tomatoes by the measurement of the three main axes, as shown in Figure 1. They also went through a weighting process. The measurements were done by employing a digital caliper $\left(316.119\right.$, MTX $\left.^{\circledR}\right)$ and the weightings were done by a digital scale (BG-440, Gehaka ${ }^{\circledR}$ ).

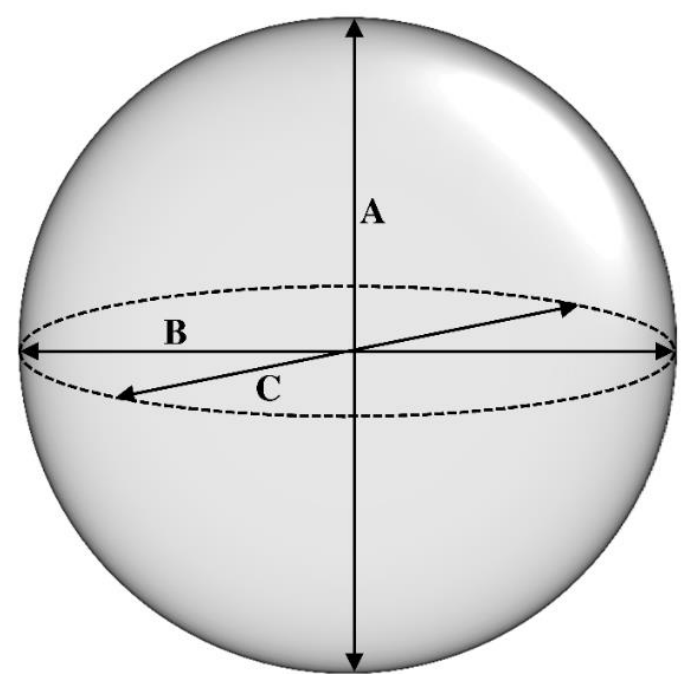

Figure 1. Representation of a triaxial spheroid tomato with thickness A, width B, and length C.

The volume $(V)\left(\mathrm{cm}^{3}\right)$ of the tomatoes were calculated by Equation (1), the sphericity $(\phi)$ by Equation $(2)$, the mean particle diameter $(\bar{D})(\mathrm{cm})$ by Equation $(3)$, the Sauter mean diameter $\left(\bar{D}_{S}\right)(\mathrm{cm})$ by Equation (4), and the specific surface area $\left(\bar{S}_{S A}\right)\left(\mathrm{cm}^{2} \cdot \mathrm{g}^{-1}\right)$ by Equation (5) $[15,16]$. The particle surface area $\left(\bar{S}_{A P}\right)\left(\mathrm{cm}^{2}\right)$ was estimated by Equation (6), the total surface area $\left(S_{T A}\right)\left(\mathrm{cm}^{2}\right)$ by Equation (7) and the total cut surface area $\left(S_{A C}\right)\left(\mathrm{cm}^{2}\right)$ by Equation (8).

$$
\begin{aligned}
& V=\frac{\pi A B C}{6} \\
& \phi=\frac{\sqrt[3]{A B C}}{A}
\end{aligned}
$$

$(2)$

(3)

$$
\bar{D}=\sqrt[3]{A B C}
$$

$$
\bar{D}_{S}=\frac{1}{\sum_{i=1}^{n} \frac{\Delta \varphi_{i}}{\bar{D}_{i}}}
$$


(5)

$$
\bar{S}_{S A}=\frac{6}{\phi \rho} \sum_{i=1}^{n} \frac{\Delta \varphi_{i}}{\bar{D}_{i}}
$$

(6)

$$
\bar{S}_{A P}=\pi \bar{D}^{2}
$$

$$
S_{T A}=\sum_{i=1}^{n} \pi \bar{D}_{i}^{2}
$$

$$
S_{A C}=\sum_{i=1}^{n} \frac{\pi\left(B_{i}+C_{i}\right)^{2}}{8}
$$

Where $A$ is the thickness (cm), $B$ is the width $(\mathrm{cm}), C$ is the length $(\mathrm{cm}), \Delta \varphi_{i}$ is the mass fraction, and $\rho$ the particle density $\left(\mathrm{g} \mathrm{cm}^{-1}\right)$. This last parameter was calculated by its own definition.

\section{Experimental System}

The experiments were conducted in a hot air-drying chamber, Figure 2 (PE 60, $\operatorname{Pardal}^{\circledR}$ ). The equipment had a drying tray made of plastic for food, with steel edges to hold the tomatoes. It also had a drying area of $0.36 \mathrm{~m}^{2}$, volume of $0.30 \mathrm{~m}^{3}$, air velocity $(v)$ of $0.11 \pm 0.02 \mathrm{~m} \cdot \mathrm{s}^{-1}$, and power of $1.3 \mathrm{~kW} \cdot \mathrm{h}^{-1}$. The ambient conditions were: air moisture content of $44.88 \pm 1.92 \%$, air temperature of $26.69 \pm 0.41^{\circ} \mathrm{C}$, and atmospheric pressure $(P)$ of $0.904 \pm 0.001$ atm.

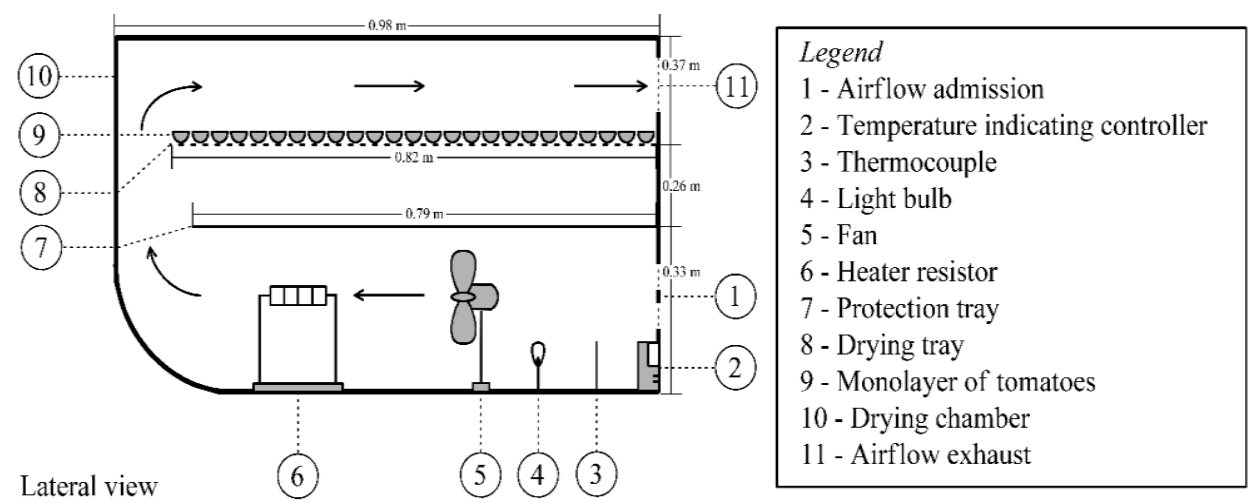

Figure 2. Experimental system for drying operation.

\section{Drying Phenomena}

\section{Drying kinetics experiments}

The drying kinetics study was performed in the drying chamber described above. The air temperatures $\left(T_{g}\right)$ were $60^{\circ} \mathrm{C}, 70^{\circ} \mathrm{C}$ and $80^{\circ} \mathrm{C}$. The tomatoes were placed on the drying tray with the cutting surface facing up, creating a monolayer. During the drying process, the tomatoes were weighted at regular times by a digital scale (DG 15, Digimed $^{\circledR}$ ), until they reached a constant weight, representing the dynamic equilibrium condition. The dry matter was measured, after the equilibrium moisture was reached, by increasing the temperature to $105^{\circ} \mathrm{C}$ and keeping it until a constant weight of the tomatoes was attained.

The total moisture $\left(\bar{X}_{t}\right)\left(\mathrm{g} \mathrm{H}_{2}{\mathrm{O} . \mathrm{g}^{-1}}\right.$ dry matter) was calculated by Equation (9), the free moisture $(\bar{X})\left(\mathrm{g} \mathrm{H}_{2} \mathrm{O} \cdot \mathrm{g}^{-1}\right.$ dry matter) by Equation (10), the moisture content ratio $(M R)$ 
by Equation (11), the drying rate $(R)\left(\mathrm{g} \mathrm{H}_{2} \mathrm{O} \cdot \mathrm{min}^{-1} \cdot \mathrm{m}^{-2}\right)$ by Equation (12), and the total time of drying $t_{t}$ (min) by Equation (13) [17].

$\bar{X}_{t}=\frac{W-W_{s}}{W_{s}}$

(9)

$$
\bar{X}=\bar{X}_{t}-X^{*}
$$

$$
M R=\frac{\bar{X}-X^{*}}{X_{i}-X^{*}}
$$

$R=-\frac{L_{S}}{S_{A C}} \frac{d \bar{X}}{d t}$

$$
t_{t}=\frac{L_{S}}{S_{A C}} \int_{X^{*}}^{X_{i}} \frac{d \bar{X}}{R}
$$

Where $W$ is the weight of the wet solid (g), $W_{s}$ is the weight of the dry matter $(\mathrm{g}), X^{*}$ is the equilibrium moisture content $\left(\mathrm{g} \mathrm{H}_{2} \mathrm{O}_{\mathrm{g}}{ }^{-1}\right.$ dry matter), $X_{i}$ is the initial moisture $\left(\mathrm{g} \mathrm{H}_{2}{\mathrm{O} . \mathrm{g}^{-1}}^{-1}\right.$ ry matter) and $L_{s}$ is the dry matter (g) at the time $t(\mathrm{~min})$.

\section{Shrinkage experiments and mathematical modeling}

In order to evaluate the deformations in the shapes of cherry and grape tomatoes, due to the removal of moisture in the drying process, the thickness shrinkage was studied. During the drying process, the thickness $(L)$ of the three half tomatoes was measured by employing a digital caliper $\left(316.119\right.$, MTX $\left.^{\circledR}\right)$ at the same times of the weightings in the drying kinetics study. The three half tomatoes were located at the beginning, in the middle, and at the end of the monolayer and presented the same mean initial thickness $\left(L_{i}\right)$ of other tomatoes in the monolayer. The thickness shrinkage index $(\Psi)$ was calculated by Equation (14).

(14)

$$
\Psi=\frac{L}{L_{i}}
$$

Several models have been postulated to elucidate the shrinkage of organic structures. Thus, four different models were selected to fit the experimental data, as described in Table 1.

Table 1 - Mathematical models to fit the thickness shrinkage data of cherry and grape tomatoes.

\begin{tabular}{clcc}
\hline Model name & \multicolumn{1}{c}{ Model } & Equation & Reference \\
\hline Linear & $\Psi=a+b \bar{X}$ & $(15)$ & {$[18]$} \\
Kaminski & $\Psi=a+b e^{-c t}$ & $(16)$ & {$[19]$} \\
Ratti & $\Psi=a+b \bar{X}+c \bar{X}^{2}+d \bar{X}^{3}$ & $(17)$ & {$[20]$} \\
Uddin & $\Psi=\left(W / W_{i}\right)^{n}$ & $(18)$ & {$[21]$} \\
\hline
\end{tabular}

$a, b, c, d, n$ : numerical constants. $W_{i}$ : initial weight of the wet solid (g). 
Effective moisture diffusivity and activation energy

The period of decreasing drying rate is almost the only one observed in the drying process of biological materials. Thus, the main mechanism of transport throughout this period is the moisture diffusion [22]. By applying a mass balance in a volume control in the interior of the porous media (monolayer of tomatoes), it is possible to write the Fick's second law of diffusion for this system, Equation (19).

$\frac{\partial X}{\partial t}=\nabla \cdot\left(D_{e f f} \nabla X\right)$

By considering that the mass transfer is in the direction of the thickness of the monolayer (z-axis) and the effective moisture diffusivity $\left(D_{\text {eff }}\right)\left(\mathrm{m}^{2} \cdot \mathrm{s}^{-1}\right)$ is constant, the Equation (19) can be rewritten as Equation (20).

$\frac{\partial X}{\partial t}=\frac{\partial}{\partial z}\left(D_{\text {eff }} \frac{\partial X}{\partial z}\right) ; \quad 0<z<L$

Adopting the boundary conditions of uniform initial $(t=0)$ moisture distribution in the monolayer (Equation (21)), impermeability at $z=0$ (Equation (22)) and equilibrium moisture at $z=L$ (Equation (23)), [23] obtained the analytic solution of Equation (20) by the variable separation method, Equation (24).

$$
\begin{array}{ll}
\text { I.C. }:\left.X(z, t)\right|_{t=0}=X_{i} ; & 0<z<L \\
\text { B.C. } 1:\left.\left[\frac{\partial X(z, t)}{\partial z}\right]\right|_{z=0}=0 ; & t>0
\end{array}
$$

$$
\text { B.C. } 2:\left.X(z, t)\right|_{z=L}=X^{*}, \quad t>0
$$

$\frac{X(z, t)-X^{*}}{X_{i}-X^{*}}=2 \sum_{n=0}^{\infty} \frac{(-1)^{n}}{\lambda_{n}} \cos \left(z \lambda_{n}\right) \exp \left[\lambda_{n}^{2} \frac{D_{e f f} t}{L^{2}}\right]$

Where $\lambda_{n}$ are the function of the eigenvalues, $n$ is the number of terms, and $L$ is the thickness of the monolayer of tomatoes (m). Inserting Equation (24) in Equation (25) and integrating it is possible to obtain Equation (26).

$$
\bar{X}(t)=\frac{1}{L} \int_{0}^{L} X(z, t)
$$

$$
M R=\frac{\bar{X}(t)-X^{*}}{X_{i}-X^{*}}=\frac{8}{\pi^{2}} \sum_{n=0}^{\infty} \frac{1}{(2 n+1)^{2}} \exp \left[-\left(n+\frac{1}{2}\right)^{2} \pi^{2} \frac{D_{e f f} t}{L^{2}}\right]
$$

The thickness shrinkage was considered by including the best model of Table 1 that describes experimental shrinkage data (Ratti model) in Equation (26) to correct the changes of $L$ at each moisture. Thus, Equation (26), with the thickness shrinkage consideration, was employed to obtain the $D_{\text {eff }}$ by utilizing the first hundred terms ( $n$ $=100$ ) of this equation. The $D_{\text {eff }}$ obtained were correlated to the air temperatures by employing the Arrhenius equation, Equation (27), to obtain the activation energy $\left(E_{a}\right)$ $\left(\right.$ J.mol $\left.{ }^{-1}\right)$. 


$$
D_{e f}=D_{0} e^{\frac{-E_{a}}{R T g}}
$$

Where $D_{0}$ is the pre-exponential factor $\left(\mathrm{m}^{2} \cdot \mathrm{s}^{-1}\right), R$ is the universal constant of gases $\left(\mathrm{J} \cdot \mathrm{K}^{-1} \cdot \mathrm{mol}^{-}\right.$ $\left.{ }^{1}\right)$, and $T_{g}$ the gas temperature (K).

\section{Mass transfer considerations}

In order to investigate the internal and external resistances related to the mass transfer, the Biot number of mass transfer $\left(B i_{m}\right)$ was evaluated by Equation (28) [17].

$$
B i_{m}=\frac{h_{m, x} V / A}{D_{e f f}}
$$

Where $h_{m, x}$ is the convective mass transfer coefficient $\left(\mathrm{m} \cdot \mathrm{s}^{-1}\right)$ and $V / A$ is the volume per surface ratio considering the monolayer of tomatoes as a flat plate $(\mathrm{m})\left(9.09 \times 10^{-3} \pm 1.98 \times 10^{-3} \mathrm{~m}\right.$ for cherry tomato and $9.07 \times 10^{-3} \pm 1.39 \times 10^{-3} \mathrm{~m}$ for grape tomato). The $h_{m, x}$ was estimated by considering a laminar flow $\left(R e_{x}=4.16 \times 10^{3}\right)$ utilizing Equation (29).

The Sherwood number $\left(S h_{x}\right)$ relates to $h_{m, x}$ by Equation (30), the Reynolds number $\left(R e_{x}\right)$ can be calculated by Equation (31), and the Schmidt number $(S c)$ by Equation (32) [24]. The binary diffusivity of moisture in air $\left(D_{m a}\right)\left(\mathrm{m}^{2} . \mathrm{s}^{-1}\right)$ was estimated by Equation (33) [25].

$S h_{x}=0.332 R e_{x}^{1 / 2} S c^{1 / 3} \quad S c \geq 0.6$

$S h_{x}=\frac{h_{m, x} x}{D_{m a}}$

$R e_{x}=\frac{\rho v x}{\mu}$

$S c=\frac{\mu}{\rho D_{m a}}$

$D_{m a}=1.87 \times 10^{-10} \mathrm{Tg}^{2.072} p^{-1}$

Where $x$ is the flat plate length $(\mathrm{m}), \rho$ is the air density $\left(\mathrm{kg} \cdot \mathrm{m}^{-3}\right), v$ is the free-stream velocity $\left(\mathrm{m} . \mathrm{s}^{-1}\right)$ and $\mu$ is the air dynamic viscosity $\left(\mathrm{N} . \mathrm{s} . \mathrm{m}^{-2}\right)$.

\section{Sensory Evaluation}

The sensory characteristics of dried cherry and grape tomatoes in olive oil were evaluated including appearance, color, aroma, oral texture, and flavor using a 5-point hedonic scale ( $5=$ liked a lot and $1=$ disliked a lot). The purchase intentions (PI) were also evaluated using a 5-point hedonic scale $(5=$ certainly would purchase and $1=$ certainly wouldn't purchase) [26]. The influence of the type of tomato (cherry and grape), air temperature $\left(60^{\circ} \mathrm{C}\right.$ and $\left.80^{\circ} \mathrm{C}\right)$, and final moisture (25\% and $35 \%$ w.b.) on 
the sensory characteristics were evaluated by a $2^{3}$ factorial experiment. The samples were prepared by the convective drying process, previously described, until the desired moisture. Then, extra virgin olive oil $\left(0.5 \%\right.$ acidity) at $90^{\circ} \mathrm{C}$ and salt were added to the dried tomatoes in the proportions of $50 \mathrm{~g}$ of dried tomato/100 $\mathrm{mL}$ olive oil/1.5 g salt, generating eight different dried tomatoes in olive oil. The tomatoes were stored for 5 days at $10^{\circ} \mathrm{C}$ until the sensory evaluation. The dried tomatoes in olive oil were subjected to sensory evaluation by a sensory panel of 50 not trained consumers older than 18 . The consumers were selected by a simple random sampling method without repetition. The samples were randomly and individually exposed to the consumers at different times. The ethical issues of the sensory evaluation were approved by the ethics committee of University Centre of Patos de Minas, Patos de Minas, Minas Gerais, Brazil, receiving the Certificate of Ethical Evaluation Presentation: 53641016.0.0000.5549.

\section{Error Analysis}

In order to analyze the differences between the experimental data $\left(y_{i}\right)$ and the data estimated by the models $\left(f\left(x_{i}\right)\right)$ employed in this paper, an error analysis was required. The coefficient of determination $\left(R^{2}\right)$, mean square error $(M S E)$, root mean square error $(R M S E)$, and chi-square $\left(\chi^{2}\right)$ were calculated by Equations. (34), (35), (36), and (37) respectively.

$$
\begin{aligned}
& R^{2}=1-\frac{\sum_{i=1}^{N}\left(y_{i}-f\left(x_{i}\right)\right)^{2}}{\sum_{i=1}^{N}\left(y_{i}-\bar{y}_{i}\right)^{2}} \\
& M S E=\sum_{i=1}^{N} \frac{\left(y_{i}-f\left(x_{i}\right)\right)^{2}}{N} \\
& R M S E=\sqrt{\sum_{i=1}^{N} \frac{\left(y_{i}-f\left(x_{i}\right)\right)^{2}}{N}} \\
& \chi^{2}=\sum_{i=1}^{N} \frac{\left(y_{i}-f\left(x_{i}\right)\right)^{2}}{f\left(x_{i}\right)}
\end{aligned}
$$

\section{Statistical Analysis}

The physicochemical and sensory data were checked for homoscedasticity by applying the Levene's test [27]. The physicochemical characteristics data that were homoscedastic $(p \geq 0.05)$ in the Levene's test were submitted to the Student- $t$ test for independent samples. On the other hand, the physicochemical data that were not homoscedastic $(p \leq 0.05)$ were submitted to the Mann-Whitney test for independent samples $[28,29]$. The sensory data were homoscedastic $(p \geq 0.05)$ for all sensory attributes and PI in the Levene's test. Thus, the sensory data were analyzed by randomized complete block design (RCBD) submitted to a two factor ANOVA with Tukey test $(p \leq 0.05)$. All the analyses were done in the software Statistica ${ }^{\circledR} 7.1$.

\section{RESULTS AND DISCUSSION}

\section{Physicochemical Characteristics}

Table 2 shows the physicochemical characteristics of fresh cherry and grape tomatoes. The initial moisture content and particle density of the cherry tomato were similar to the values obtained by $[15,30]$. The mass of the cherry tomato was close to the value reported by [31] and the mean diameter and specific surface area were similar to those described by [15]. For the grape tomato, the values of volume and mass were close to those reported by [32] and [31], respectively. 
Table 2 - Physicochemical parameters of fresh cherry and grape tomatoes*.

\begin{tabular}{llll}
\hline Parameters & Cherry tomato & Grape tomato & $p$ \\
\hline$X_{i}(\% \mathrm{w} . \mathrm{b})$. & $85.85 \pm 1.29$ & $84.80 \pm 0.91$ & 0.14788 \\
$\rho\left(\mathrm{g} . \mathrm{cm}^{-3}\right)$ & $1.22 \pm 0.00$ & $1.23 \pm 0.00$ & 0.00001 \\
$W(\mathrm{~g})$ & $11.69 \pm 0.33$ & $6.46 \pm 0.12$ & 0.00000 \\
$V\left(\mathrm{~cm}^{3}\right)$ & $9.66 \pm 0.29$ & $5.28 \pm 0.10$ & 0.00000 \\
$\phi(-)$ & $0.95 \pm 0.00$ & $0.81 \pm 0.00$ & 0.00000 \\
$\bar{D}(\mathrm{~cm})$ & $2.60 \pm 0.03$ & $2.14 \pm 0.01$ & 0.00000 \\
$\bar{D}_{S}(\mathrm{~cm})$ & $2.68 \pm 0.31$ & $2.18 \pm 0.16$ & 0.00727 \\
$\bar{S}_{S A}\left(\mathrm{~cm}^{2} . \mathrm{g}^{-1}\right)$ & $1.95 \pm 0.18$ & $2.79 \pm 0.13$ & 0.00019 \\
$\bar{S}_{A P}\left(\mathrm{~cm}^{2}\right)$ & $22.00 \pm 5.97$ & $14.60 \pm 2.32$ & 0.01536 \\
$S_{T A}\left(\mathrm{~cm}^{2}\right)$ & $3799.36 \pm 353.87$ & $4655.23 \pm 273.64$ & 0.00256 \\
$S_{A C}\left(\mathrm{~cm}^{2}\right)$ & $1882.54 \pm 398.92$ & $1872.70 \pm 260.41$ & 0.94564 \\
\hline
\end{tabular}

*Mean values $\pm 95 \%$ confidence interval. $p$ is the probability value from the Student- $t$ or Mann-Whitney tests.

Comparing both types of tomatoes it is possible to realize that they are similar in terms of particle density and not significantly different for initial moisture content and surface area of the cut. The main differences between them were found in the mass, volume, sphericity, mean diameter, Sauter mean diameter, specific surface area, particle surface area, and total surface area. The cherry tomato had characteristics of a sphere whereas the grape tomato had an ellipsoid shape with lower sphericity. The grape tomato also presented a smaller mass, shorter diameter, smaller volume, and smaller particle surface area. However, it had a larger specific surface area and a larger total surface area.

\section{Drying Phenomena}

\section{Drying kinetics and mass transfer phenomena}

The drying curves and the drying rate curves can be seen in Figure 3 (A) and (B) for the cherry tomato and Figure $3(\mathrm{C})$ and (D) for the grape tomato. The $t_{t}$ and $X^{*}$ ranged

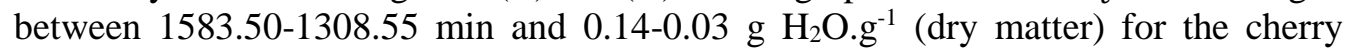
tomato and 1551.24-1227.44 min and 0.15-0.06 $\mathrm{g} \mathrm{H}_{2} \mathrm{O}_{\mathrm{g}} \mathrm{g}^{-1}$ (dry matter) for the grape tomato. Analyzing the drying rate curves it is possible to observe small constant-rate drying periods followed by two falling rate-drying periods. This behavior suggests the existence of low surface moisture content that was rapidly removed. Then, the drying processes occurred preferably in the falling rate-drying periods and the diffusion of the moisture throughout the structure of the material is slow enough to control the drying rate. A similar behavior was also observed by $[9,15,33]$. In order to deeply investigate the mass transfer phenomena suggested by the drying rate curves the $D_{\text {eff }}$ were estimated. The values of this parameter are displayed in Table 3 for the cherry and grape tomatoes. The values of $R^{2}, \chi^{2}, M S E$ and $R M S E$ showed the applicability of the Fick's second law with the thickness shrinkage consideration. The values of $D_{\text {eff }}$ were close to those reported by $[4,8,9,33]$. The $B i_{m}$ ranged between $8.26 \times 10^{3} \pm 1.97 \times 10^{3}$ for cherry tomato and $7.37 \times 10^{3} \pm 1.50 \times 10^{3}$ for grape tomato. According to [34], these values indicates that the internal mass resistance control the mass transfer of the drying process $\left(B i_{m}>50\right)$, as suggested by the drying rate curves and validating the hypotheses considered in the drying kinetics modeling. In this case, [9] suggest that the water movement mechanism in the tomato's inner structure is mostly by trans-membrane transport and cell wall pathway in the first falling ratedrying period and symplastic transport way in the second period. 

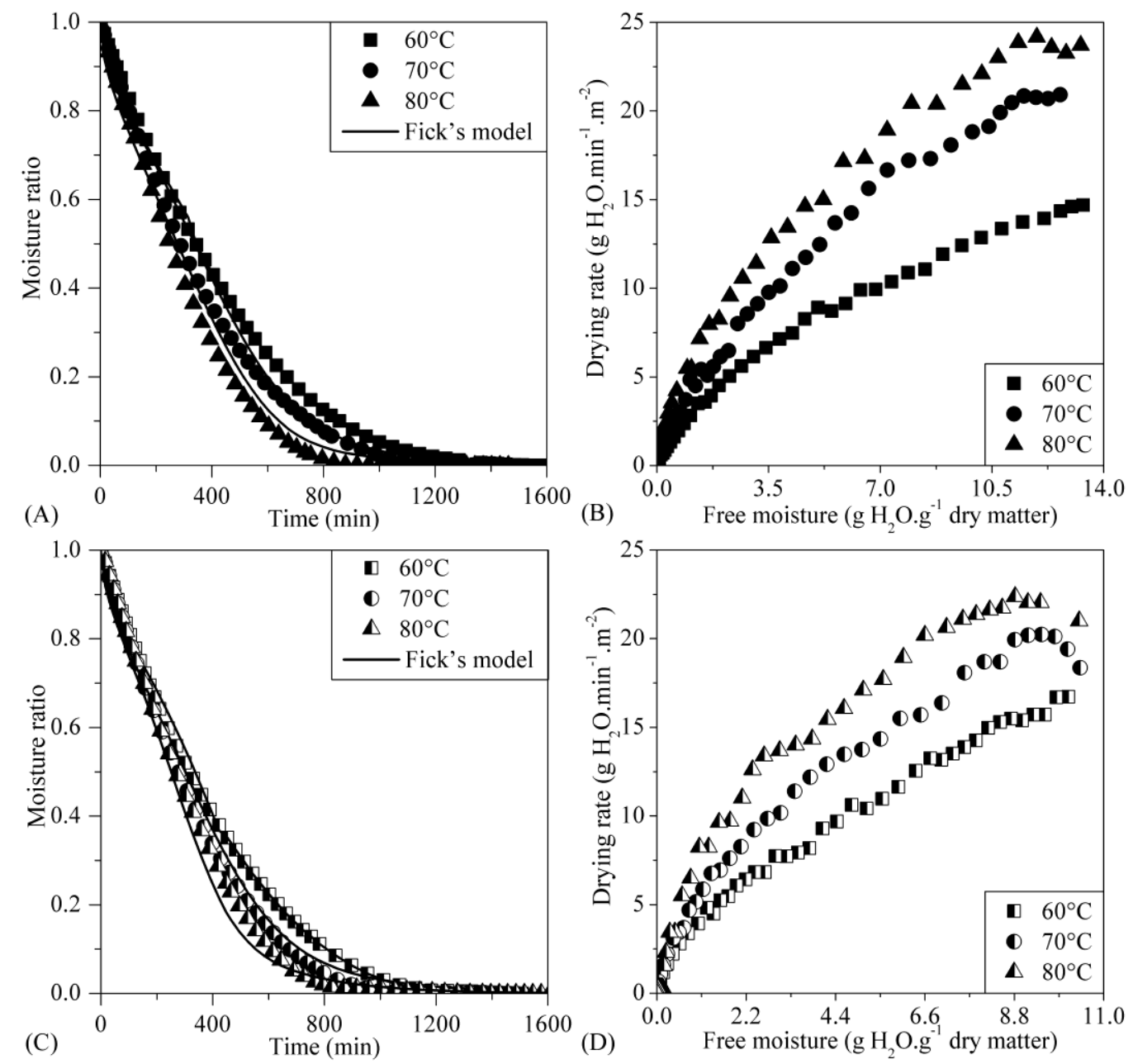

Figure 3. Drying curves for cherry (A) and grape (C) tomatoes with the Fick's model fitted and the drying rate curves for cherry (B) and grape (D) tomatoes.

Table 3 - Estimated effective moisture diffusivities of the convective drying process of cherry and grape tomatoes.

\begin{tabular}{|c|c|c|c|c|c|c|}
\hline \multirow{2}{*}{ Parameters } & \multicolumn{3}{|c|}{ Cherry tomato } & \multicolumn{3}{|c|}{ Grape tomato } \\
\hline & $60^{\circ} \mathrm{C}$ & $70^{\circ} \mathrm{C}$ & $80^{\circ} \mathrm{C}$ & $60^{\circ} \mathrm{C}$ & $70^{\circ} \mathrm{C}$ & $80^{\circ} \mathrm{C}$ \\
\hline$D_{e f f}\left(\mathrm{~m}^{2} \cdot \mathrm{s}^{-1}\right)$ & $6.08 \times 10^{-10}$ & $8.96 \times 10^{-10}$ & $1.16 \times 10^{-9}$ & $7.80 \times 10^{-10}$ & $9.50 \times 10^{-10}$ & $1.17 \times 10^{-9}$ \\
\hline$R^{2}$ & 0.9840 & 0.9900 & 0.9903 & 0.9807 & 0.9942 & 0.9902 \\
\hline$\chi^{2}$ & 965.6524 & 0.2033 & 0.3633 & 2.6463 & 0.2919 & 0.2831 \\
\hline$M S E$ & 0.0018 & 0.0011 & 0.0010 & 0.0022 & 0.0007 & 0.0011 \\
\hline$R M S E$ & 0.0419 & 0.0330 & 0.0323 & 0.0464 & 0.0257 & 0.0333 \\
\hline
\end{tabular}

Another interesting effect observed is the increase in the drying rates as the temperature increased, resulting in more inclined drying curves, lower $t_{t}$ and higher $D_{e f f}$. This effect can be attributed to the increase of the heat transfer potential between the air and the tomato structure in high temperatures, facilitating the moisture removal [35]. The effect of the temperature on the drying kinetics is well known in the literature as reported by $[4,9,33]$.

By comparing the drying kinetics of both types of tomatoes, it is possible to notice a very similar behavior. However, as showed by the drying rate curves, drying curves, $t_{t}$ and $D_{e f f}$, the grape tomato had a faster drying process. Many factors can influence the faster drying of this type of tomato, but since the operational conditions were equally 
provided to both tomato types, the physicochemical characteristics were the main responsible. In fact, the characterization showed that the grape tomato had a higher specific surface area and a higher total surface area. The high surface area of the solid phase favors the effective contact with the gaseous phase, increasing the heat and mass transfer [36]. Furthermore, comparing the activation energy of both tomatoes in Table 4 , it is clear that the grape tomato had a lower minimum energy to make the drying process possible. Then, the own internal structure of the grape tomato, alongside with a higher surface area, can promote faster mobility of the water molecules through the material structure, easier removal of moisture, and a faster drying process.

Table 4 - Estimated activation energies of the convective drying process of cherry and grape tomatoes.

\begin{tabular}{lcc}
\hline Parameters & Cherry tomato & Grape tomato \\
\hline$E_{a}\left(\mathrm{~J}^{\mathrm{mol}} \mathrm{mo}^{-1}\right)$ & $3.16 \times 10^{4}$ & $1.98 \times 10^{4}$ \\
$D_{0}\left(\mathrm{~m}^{2} \cdot \mathrm{s}^{-1}\right)$ & $5.67 \times 10^{-5}$ & $9.95 \times 10^{-7}$ \\
$R^{2}$ & 0.9903 & 0.9989 \\
$\chi^{2}$ & 0.7367 & 4.2547 \\
$M S E$ & 0.0007 & 0.0001 \\
$R M S E$ & 0.0261 & 0.0054 \\
\hline
\end{tabular}

Shrinkage phenomena and modeling

In Figure 4 it is possible to notice the shrinkage behavior of cherry and grape tomatoes for different moisture conditions and temperatures. As expected, the thickness shrinkage of the monolayer of tomatoes increased as the moisture decreased for both tomatoes, suggesting that the phenomenon of shrinkage is mainly ruled by moisture loss. By comparing both tomatoes it is possible to notice a similar shrinkage behavior, except for the temperature of $60^{\circ} \mathrm{C}$ in which the cherry tomato showed a higher shrinkage, indicating that the outer layers of this fruit were more flexible than the grape tomato ones at a lower temperature [37].
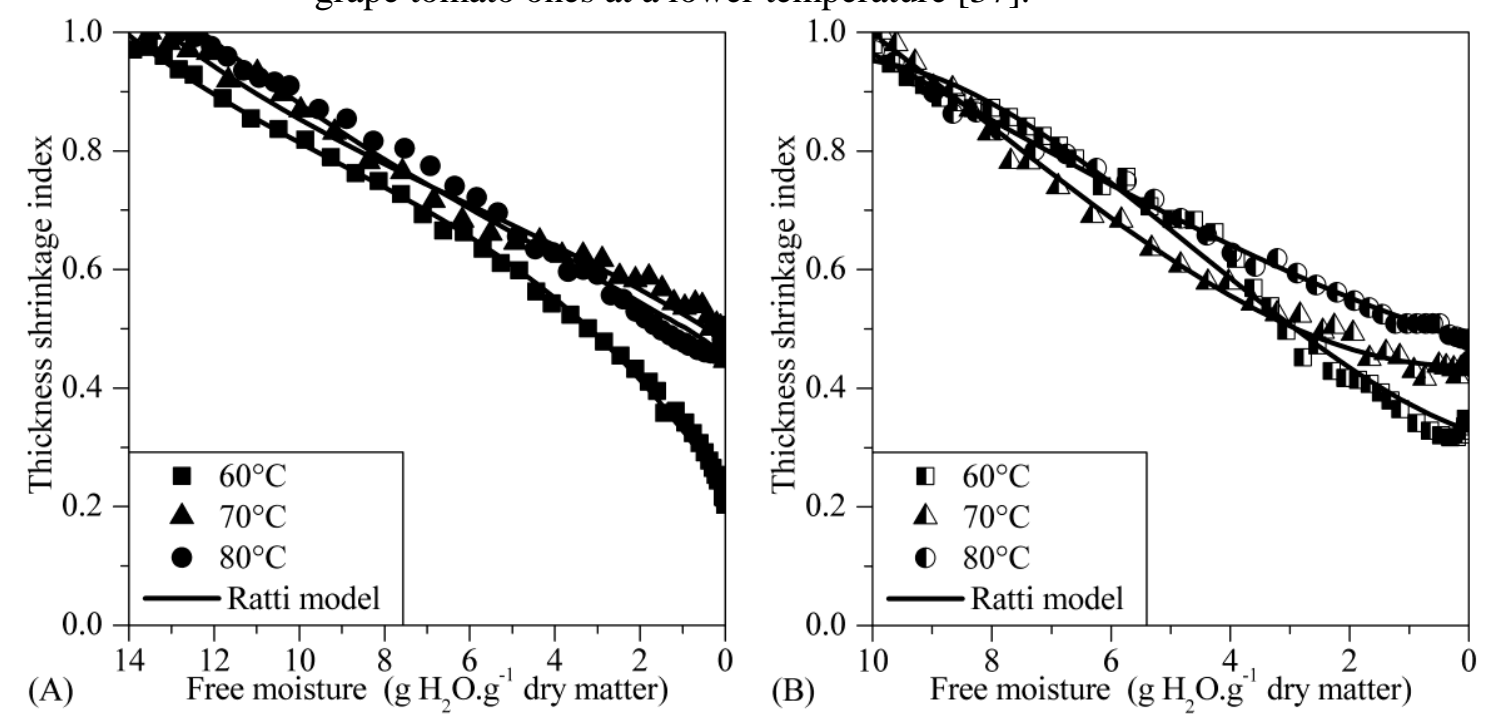

Figure 4. Thickness shrinkage data for cherry (A) and grape (B) tomatoes with the Ratti model fitted.

Table 5 describes the results of the applications of shrinkage models to the thickness shrinkage data of the monolayer of both cherry and grape tomatoes. The Ratti model exhibited the highest values of $R^{2}$ and the low values of $\chi^{2}, M S E$, and RMSE, at all temperatures for the cherry and grape tomatoes. This model was proposed by [20] as a simple third-order polynomial equation for the description of the shrinkage volume and area of potato, apple, and carrot. Nevertheless, in Figure 4 it is possible to 
perceive that this model is well applicable for thickness shrinkage of cherry and grape tomatoes.

Table 5 - The parameters of the mathematical models fitted to the thickness shrinkage data of cherry and grape tomatoes.

\begin{tabular}{|c|c|c|c|c|c|c|c|}
\hline \multirow{2}{*}{ Model } & \multirow{2}{*}{ Parameters } & \multicolumn{3}{|c|}{ Cherry tomato } & \multicolumn{3}{|c|}{ Grape tomato } \\
\hline & & $60^{\circ} \mathrm{C}$ & $70^{\circ} \mathrm{C}$ & $80^{\circ} \mathrm{C}$ & $60^{\circ} \mathrm{C}$ & $70^{\circ} \mathrm{C}$ & $80^{\circ} \mathrm{C}$ \\
\hline \multirow{6}{*}{ Linear } & $a$ & 0.27 & 0.45 & 0.48 & 0.32 & 0.47 & 0.41 \\
\hline & $b$ & 0.05 & 0.04 & 0.04 & 0.07 & 0.05 & 0.05 \\
\hline & $R^{2}$ & 0.9757 & 0.9961 & 0.9847 & 0.9848 & 0.9926 & 0.9602 \\
\hline & $x^{2}$ & 5.5836 & 0.9034 & 0.5707 & 3.7231 & 0.6444 & 1.0418 \\
\hline & $M S E$ & 0.0543 & 0.0127 & 0.0082 & 0.0416 & 0.0096 & 0.0140 \\
\hline & $R M S E$ & 0.2329 & 0.1128 & 0.0908 & 0.2040 & 0.0978 & 0.1183 \\
\hline \multirow{7}{*}{ Kaminski } & $a$ & 0.04 & 0.42 & 0.38 & 0.28 & 0.46 & 0.43 \\
\hline & $b$ & 0.97 & 0.61 & 0.60 & 0.75 & 0.56 & 0.60 \\
\hline & $c$ & $1.18 \times 10^{-3}$ & $2.49 \times 10^{-3}$ & $1.86 \times 10^{-3}$ & $2.19 \times 10^{-3}$ & $3.13 \times 10^{-3}$ & $4.50 \times 10^{-3}$ \\
\hline & $R^{2}$ & 0.9979 & 0.9895 & 0.9744 & 0.9741 & 0.9942 & 0.9924 \\
\hline & $x^{2}$ & 0.0180 & 0.0295 & 0.0600 & 0.1326 & 0.0127 & 0.0215 \\
\hline & MSE & 0.0001 & 0.0004 & 0.0008 & 0.0014 & 0.0002 & 0.0002 \\
\hline & $R M S E$ & 0.0120 & 0.0191 & 0.0276 & 0.0372 & 0.0130 & 0.0153 \\
\hline \multirow{8}{*}{ Ratti } & $a$ & 0.23 & 0.45 & 0.48 & 0.33 & 0.48 & 0.44 \\
\hline & $b$ & 0.11 & 0.03 & 0.05 & 0.04 & 0.03 & 0.00 \\
\hline & $c$ & $-7.54 \times 10^{-3}$ & $3.02 \times 10^{-3}$ & $-2.28 \times 10^{-3}$ & $1.01 \times 10^{-2}$ & $2.68 \times 10^{-3}$ & $1.01 \times 10^{-2}$ \\
\hline & $d$ & $2.75 \times 10^{-4}$ & $-1.77 \times 10^{-4}$ & $1.30 \times 10^{-4}$ & $-7.42 \times 10^{-4}$ & $-9.40 \times 10^{-5}$ & $-4.08 \times 10^{-4}$ \\
\hline & $R^{2}$ & 0.9981 & 0.9978 & 0.9862 & 0.9908 & 0.9976 & 0.9950 \\
\hline & $\chi^{2}$ & 0.0182 & 0.0060 & 0.0361 & 0.0442 & 0.0047 & 0.0136 \\
\hline & $\hat{M S E}$ & 0.0001 & 0.0001 & 0.0004 & 0.0005 & 0.0001 & 0.0002 \\
\hline & $R M S E$ & 0.0114 & 0.0087 & 0.0206 & 0.0225 & 0.0083 & 0.0127 \\
\hline \multirow{5}{*}{ Uddin } & $n$ & 0.56 & 0.36 & 0.31 & 0.57 & 0.37 & 0.44 \\
\hline & $R^{2}$ & 0.9976 & 0.9294 & 0.9048 & 0.9618 & 0.8716 & 0.7381 \\
\hline & $x^{2}$ & 0.0211 & 0.2344 & 0.1940 & 1.8745 & 0.2836 & 0.6418 \\
\hline & $\hat{M S E}$ & 0.0002 & 0.0025 & 0.0028 & 0.0236 & 0.0037 & 0.0082 \\
\hline & $R M S E$ & 0.0127 & 0.0501 & 0.0526 & 0.1535 & 0.0611 & 0.0905 \\
\hline
\end{tabular}

\section{Sensory Preferences}

The statistical results of the sensory evaluation are displayed in Table 6 for the different drying conditions. The treatments were statistically different $(p<0.05)$ and had mean scores above 2.5 for all sensory characteristics and PI. These results indicate that the operational conditions had effects on the sensory preferences and the final product was well accepted by the customers. The treatment 5 showed the best mean scores for all sensory characteristics and PI.

The results displayed in Table 6 were statistically analyzed according to the factorial experiment. The effects of the factors with a significance level lower than 0.05 showed that only the type of the tomato and the air temperature had significant effect on the sensory preferences of the consumers. The type of the tomato was the most potent factor for appearance and aroma, while the air temperature showed to be the most important factor for color, oral texture, flavor, and PI. The results also indicated a trend of preference of cherry tomato and air temperature of $60^{\circ} \mathrm{C}$.

Table 6 - Response variables of the sensory evaluation of dried cherry and grape tomatoes in olive oil*

\begin{tabular}{llcccccccc}
\hline$\#$ & $\begin{array}{c}\text { Tomato } \\
\text { types }\end{array}$ & $\begin{array}{c}T_{g} \\
\left({ }^{\circ} \mathrm{C}\right)\end{array}$ & $\begin{array}{c}\bar{X} \\
(\% \text { w.b. })\end{array}$ & $\begin{array}{c}\text { Appearance } \\
\text { Color }\end{array}$ & Aroma & Oral texture & Flavor & PI \\
\hline 1 & Cherry & 60.0 & 25.0 & $3.68 \pm 0.30^{\mathrm{a}, \mathrm{b}}$ & $4.16 \pm 0.25^{\mathrm{a}, \mathrm{c}}$ & $3.74 \pm 0.29^{\mathrm{a}, \mathrm{b}}$ & $3.76 \pm 0.27^{\mathrm{a}, \mathrm{c}}$ & $3.46 \pm 0.36^{\mathrm{a}, \mathrm{b}}$ & $3.56 \pm 0.27^{\mathrm{b}, \mathrm{c}}$ \\
2 & Grape & 60.0 & 25.0 & $3.52 \pm 0.29^{\mathrm{a}, \mathrm{b}}$ & $4.12 \pm 0.24^{\mathrm{a}, \mathrm{c}}$ & $3.56 \pm 0.26^{\mathrm{a}, \mathrm{b}}$ & $3.30 \pm 0.26^{\mathrm{a}, \mathrm{b}, \mathrm{c}}$ & $3.38 \pm 0.35^{\mathrm{a}, \mathrm{b}}$ & $3.14 \pm 0.28^{\mathrm{a}, \mathrm{b}, \mathrm{c}}$ \\
3 & Cherry & 80.0 & 25.0 & $3.44 \pm 0.31^{\mathrm{a}, \mathrm{b}}$ & $3.80 \pm 0.32^{\mathrm{a}, \mathrm{b}}$ & $3.64 \pm 0.28^{\mathrm{a}, \mathrm{b}}$ & $3.48 \pm 0.35^{\mathrm{a}, \mathrm{b}, \mathrm{c}} 3.12 \pm 0.35^{\mathrm{a}, \mathrm{b}}$ & $3.12 \pm 0.34^{\mathrm{a}, \mathrm{b}, \mathrm{c}}$ \\
4 & Grape & 80.0 & 25.0 & $3.08 \pm 0.28^{\mathrm{a}}$ & $3.70 \pm 0.27^{\mathrm{a}, \mathrm{b}}$ & $3.32 \pm 0.30^{\mathrm{a}}$ & $3.08 \pm 0.29^{\mathrm{a}}$ & $2.74 \pm 0.34^{\mathrm{a}}$ & $2.60 \pm 0.32^{\mathrm{a}}$ \\
5 & Cherry & 60.0 & 35.0 & $4.04 \pm 0.28^{\mathrm{b}}$ & $4.44 \pm 0.22^{\mathrm{c}}$ & $4.06 \pm 0.22^{\mathrm{b}}$ & $3.80 \pm 0.28^{\mathrm{c}}$ & $3.76 \pm 0.32^{\mathrm{b}}$ & $3.68 \pm 0.29^{\mathrm{c}}$ \\
6 & Grape & 60.0 & 35.0 & $3.68 \pm 0.27^{\mathrm{a}, \mathrm{b}}$ & $4.02 \pm 0.22^{\mathrm{a}, \mathrm{c}}$ & $3.46 \pm 0.26^{\mathrm{a}}$ & $3.16 \pm 0.29^{\mathrm{a}, \mathrm{b}}$ & $2.72 \pm 0.37^{\mathrm{a}}$ & $2.70 \pm 0.35^{\mathrm{a}}$
\end{tabular}




\begin{tabular}{|c|c|c|c|c|c|c|c|}
\hline 7 & Cherry & 80.0 & 35.0 & $3.56 \pm 0.40^{\mathrm{a}, \mathrm{b}}$ & $3.64 \pm 0.36^{\mathrm{a}, \mathrm{b}}$ & $3.56 \pm 0.31^{\mathrm{a}, \mathrm{b}} 3.36 \pm 0.32^{\mathrm{a}, \mathrm{b}, \mathrm{c}} 3.16 \pm 0.40^{\mathrm{a}, \mathrm{b}}$ & $3.10 \pm 0.36^{\mathrm{a}, \mathrm{b}, \mathrm{c}}$ \\
\hline 8 & Grape & 80.0 & 35.0 & $3.14 \pm 0.36^{\mathrm{a}}$ & $3.38 \pm 0.33^{\mathrm{b}}$ & $3.36 \pm 0.27^{\mathrm{a}} \quad 3.26 \pm 0.34^{\mathrm{a}, \mathrm{b}, \mathrm{c}} 2.98 \pm 0.37^{\mathrm{a}}$ & $2.88 \pm 0.39^{\mathrm{a}, \mathrm{b}}$ \\
\hline
\end{tabular}

"Mean values $\pm 95 \%$ confidence interval. Values designated by the different letters are different $(p<0.05)$ within columns.

The preference for cherry tomato was commented by some judges due to its larger dimensions and better aroma, providing a more appetizing product. In fact, [38] demonstrated that the fresh cherry tomato releases more key volatiles responsible for the "green" aroma, such as (Z)-3-hexanal and (E)-2-hexanal, than grape tomato during chewing. Nevertheless, [39] showed that the convective drying process can modify the volatile profile of cherry tomato by the degradation of those key volatiles and generation of new compounds, by Maillard reactions and catabolism of carotenoids, which are related to the cook flavor. In addition, [38] showed that the own chewing process can modify the volatile profile of cherry and grape tomatoes. Thus, several factors are responsible for the better aroma of cherry tomato observed, and the main differences in the modifications of the volatile profiles of cherry and grape tomato, due to the convective drying and chewing processes still remain unclear in the literature.

The influence of temperature can be related to the coloring and flavor changes, once [9] showed that the decrease of the drying air temperature from $70^{\circ} \mathrm{C}$ to $50^{\circ} \mathrm{C}$ resulted in less darkening of the tomatoes and increase in the sugar/acid ratio. These improvements may produce dried tomatoes with better color and flavor, resulting in better PI.

Thus, although the grape tomato and the air temperature of $80^{\circ} \mathrm{C}$ provided a faster drying process, considering the sensory preferences, the cherry tomato dried at $60^{\circ} \mathrm{C}$ until the final moisture of $35 \%$ w.b. was the most recommended for the production of dried tomatoes in olive oil.

\section{CONCLUSIONS}

The convective drying process of cherry and grape tomatoes for dried tomato production was studied taking into account operational and sensorial aspects. The physicochemical characterization showed that the fresh cherry tomato had characteristics of a sphere, while the fresh grape tomato had an ellipsoid shape. The drying kinetics demonstrated that the drying processes occurred preferably in falling rate-drying periods and the diffusion of the moisture throughout the structure of the material is slow enough to control the drying rate. The increase in the air temperature resulted in more inclined drying curves, lower total times of drying and higher effective moisture diffusions. The grape tomato showed a faster drying process, which was attributed to its higher surface area and its internal structure. The thickness shrinkage and drying curves were better described by the Ratti and Fick's model, respectively, for both types of tomato. The sensory evaluation exhibited that the cherry tomato, dried at lower air temperatures, provided better sensorial characteristics and higher purchasing intention, whereas the final moisture had no effect. Thus, although the grape tomato, dried at the air temperature of $80^{\circ} \mathrm{C}$, provided a faster drying process considering the sensory preferences, the cherry tomato, dried at $60^{\circ} \mathrm{C}$ until the final moisture of $35 \%$ w.b., was the most recommended for the production of dried tomatoes in olive oil. 


\section{ACKNOWLEDGEMENTS}

The authors would like to gratefully acknowledge University Centre of Patos de Minas for the financial support of this paper.

\section{REFERENCES}

1. FAOSTAT. Food and Agriculture Organization of the United Nations. 2014. Available from: http://www.fao.org/faostat/en/\#data

2. Sousa AS, Borges SV, Magalhães NF, Ricardo HV, Azevedo AD. Spray-dried tomato powder: Reconstitution properties and colour. Brazilian Arch Biol Technol. 2008; 51 (4): $807-14$.

3. Akanbi CT, Adeyemi RS, Ojo A. Drying characteristics and sorption isotherm of tomato slices. J Food Eng. 2006; 73 (2): 157-63.

4. Doymaz I. Air-drying characteristics of tomatoes. J Food Eng. 2007; 78: 1291-7.

5. Pérez-Rodríguez F, Carrasco E, Valero A. Impact of dehydration and drying operations on the microbial ecology of foods. In: Quantitative Microbiology in Food Processing. Chichester: John Wiley \& Sons; 2016. p. 160-75.

6. Mujumdar AS. Handbook of Industrial Drying. Boca Raton: CRC Press. 2014. 1288 p.

7. Doymaz İ, Özdemir Ö. Effect of air temperature, slice thickness and pretreatment on drying and rehydration of tomato. Int J Food Sci Technol. 2014; 49 (2): 558-64.

8. Bennamoun L, Khama R, Léonard A. Convective drying of a single cherry tomato: Modeling and experimental study. Food Bioprod Process. 2015; 94: 114-23.

9. Purkayastha M Das, Nath A. Thin layer drying of tomato slices. J Food Sci Technol. 2013; 50: 642-53.

10. May E. Tomato raisin. United States; US 6743460 B2, 2004. p. 4. Available from: https://www.google.com/patents/US6743460

11. Orlandin A, Fontana RC, Sandri IG. Estudo de pré-tratamentos na desidratação de tomatecereja (Lycopersicon esculentum var. cerasiforme). Brazilian J Food Technol. 2010; 13(3): 226-31.

12. Coyago-Cruz E, Corell M, Moriana A, Hernanz D, Stinco CM, Meléndez-Martínez AJ. Effect of the fruit position on the cluster on fruit quality, carotenoids, phenolics and sugars in cherry tomatoes (Solanum lycopersicum L.). Food Res Int. 2017; 100: 804-13.

13. Azoubel PM, Murr FEX. Mass transfer kinetics of osmotic dehydration of cherry tomato. J Food Eng. 2004; 61 (3): 291-5.

14. Heredia A, Barrera C, Andrés A. Drying of cherry tomato by a combination of different dehydration techniques. Comparison of kinetics and other related properties. J Food Eng. 2007; 80 (1): 111-8.

15. Lourenço GA, Finzer JRD. Secagem parcial de tomate-cereja em secador de bandejas vibradas com reciclo. Brazilian J Food Technol. 2013; 16 (4): 334-45.

16. Mohsenin N. Physical properties of plant and animal materials. New York: Gordon and Breach; 1970. $841 \mathrm{p}$.

17. Geankoplis CJ. Transport Processes and Unit Operations. Englewood Cliffs: Prentice Hall International; $1993.937 \mathrm{p}$.

18. Wang N, Brennan JG. Changes in structure, density and porosity of potato during dehydration. J Food Eng. 1995; 24 (1): 61-76.

19. Mayor L, Sereno AM. Modelling shrinkage during convective drying of food materials: A review. J Food Eng. 2004; 61 (3): 373-86.

20. Ratti C. Shrinkage during drying of foodstuffs. J Food Eng. 1994; 23 (1): 91-105.

21. Uddin MS, Hawlader MNA, Rahman MS. Evaluation of drying characteristics of pineapple in the production of pineapple powder. J Food Process Preserv. 1990; 14 (5): 375-91.

22. Park KJ, Ardito TH, Ito AP, Park KJB, Oliveira RA, Chiorato M. Effective Diffusivity Determination Considering Shrinkage by Means of Explicit Finite Difference Method. Dry 
Technol. 2007; 25 (7-8): 1313-9.

23. Crank J. The mathematics of diffusion. Oxford: Oxford Univ Press. 1975. p. 414.

24. Incropera FP, DeWitt DP, Bergman TL, Lavine AS. Fundamentals of Heat and Mass Transfer. Hoboken: John Wiley \& Sons; 2006. 1070 p.

25. Marrero TR, Mason EA. Gaseous Diffusion Coefficients. J Phys Chem Ref Data. 1972; 1(1): 3-118.

26. Lawless HT, Heymann H. Sensory Evaluation of Food: principles and practic. New York: Springer Science+Business Media. 1999. 842 p.

27. Levene H. Robust tests for equality of variances. In Contributions to Probability and Statistics: Essays in Honor of Harold Hotelling. Stanford Univ Press. 1960; 278-92.

28. Granato D, Araújo Calado VM, Jarvis B. Observations on the use of statistical methods in Food Science and Technology. Food Res Int. 2014; 55: 137-49.

29. Mann HB, Whitney DR. On a Test of Whether one of Two Random Variables is Stochastically Larger than the Other. Ann Math Stat. 1947; 18 (1): 50-60.

30. Azoubel PM, Murr FEX. Mathematical modelling of the osmotic dehydration of cherry tomato (Lycopersicon esculentum var. cerasiforme). Ciênc Tecnol Aliment. 2000; 20 (2): 228-32.

31. Sun X, Zhou B, Luo Y, Ference C, Baldwin E, Harrison K, et al. Effect of controlledrelease chlorine dioxide on the quality and safety of cherry/grape tomatoes. Food Control . 2017; 82: 26-30.

32. Xanthopoulos GT, Athanasiou AA, Lentzou DI, Boudouvis AG, Lambrinos GP. Modelling of transpiration rate of grape tomatoes: Semi-empirical and analytical approach. Biosyst Eng . 2014; 124: 16-23.

33. Workneh TS, Oke MO. Thin Layer Modelling of Microwave-Convective Drying of Tomato Slices. Int J Food Eng. 2013; 9(1): 75-90.

34. Strumillo C, Kudra T. Drying: Principles, Applications, and Design. Montreux: Gordon and Breach Science Publishers; 1986. 448 p.

35. Chiang WC, Petersen JN. Thin layer air drying of French fried potatoes. Int J Food Sci Technol . 1985; 20 (1): 67-78.

36. Dinçer İ, Zamfirescu C. Drying Phenomena. Chichester: John Wiley \& Sons; 2015. 511 p.

37. McMinn WAM, Magee TRA. Physical characteristics of dehydrated potatoes - Part I. J Food Eng. 1997; 33 (1-2): 37-8.

38. Xu Y, Barringer S. Comparison of Volatile Release in Tomatillo and Different Varieties of Tomato during Chewing. J Food Sci. 2010; 75 (4): C352-8.

39. Heredia A, Peinado I, Rosa E, Andrés A, Escriche I. Volatile profile of dehydrated cherry tomato: Influences of osmotic pre-treatment and microwave power. Food Chem. 2012; 130 (4): 889-95. 